\title{
ÓBITOS RELACIONADOS À SÍNDROME DA IMUNODEFICIÊNCIA ADQUIRIDA NO BRASIL, 2013 A 2017
}

DEATHS RELATED TO ACQUIRED IMMUNODEFICIENCY SYNDROME

OUTSIDE BRAZIL, 2013 TO 2017

MUERTES RELACIONADAS CON EL SÍNDROME DE INMUNODEFICIENCIA

ADQUIRIDA FUERA DE BRASIL, 2013 A 2017

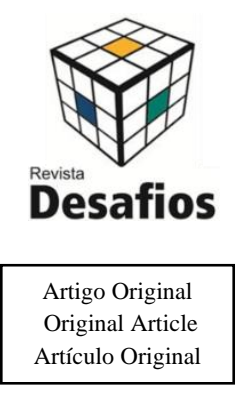

Hélida Maravilha Dantas e Sousa Almeida*1, Ana Cecília Alexandre Dos

Ramos $^{1}$, Arydyjany Gonçalves Nascimento ${ }^{2}$, Jéssika Lopes Figueiredo

Pereira Batista ${ }^{3}$, Viviane Fernandes De Sousa ${ }^{1}$, Rafaela Rolim De

Oliveira $^{4}$, Francisca Patrícia Barreto de Carvalho ${ }^{2}$

${ }^{1}$ Bacharelado em Enfermagem, Centro de Formação de Professores, Universidade Federal de Campina Grande, Cajazeiras-PB, Brasil.

${ }^{2}$ Programa de Pós-Graduação em Saúde e Sociedade, Universidade do Estado do Rio Grande do Norte, Mossoró-RN, Brasil.

${ }^{3}$ Programa de Pós-Graduação em Saúde Pública, Universidade Estadual da Paraíba, Campina Grande-PB, Brasil.

${ }^{4}$ Faculdade Santa Maria de Cajazeiras, Cajazeiras-PB, Brasil.

*Correspondência: Universidade Federal de Campina Grande, R. Pedro Carlos de Moraes Lot. Jose Bonifacio de Moura, Cajazeiras, Paraíba, Brasil. CEP: 58900-000. e-mail:

helidacaico@hotmail.com

Artigo recebido em 21/03/2021 aprovado em 17/05/2021 publicado em 20/10/2021.

\section{RESUMO}

Caracterizado como um grande problema de saúde pública mundial, a infecção pelo Vírus da Imunodeficiência Humana necessita de constantes estudos para identificar a evolução da mortalidade. Este estudo vislumbra expor o perfil sociodemográfico dos óbitos pela Síndrome da Imunodeficiência Adquirida no Brasil. Possui desenho epidemiológico, transversal e retrospectivo, com abordagem quantitativa, realizado em novembro de 2019 a partir de dados do Sistema de Informação de Mortalidade, referentes ao período de 2013 a 2017, considerando as variáveis: região, faixa etária, sexo, raça/cor e escolaridade. A amostra foi constituída por 62.081 casos de óbito pela aids, com destaque para a região Sudeste com 42,96\%, na faixa etária de 60 a 64 anos (29,33\%), do sexo masculino (66,25\%), com prevalência na variável raça/cor parda (42\%), apresentando de 4 a 7 anos de estudo (25,48\%). Foi revelado uma mudança no perfil desses óbitos no país, não existindo uma população mais vulnerável.

Palavras-chave: Epidemiologia; Mortalidade; Síndrome da Imunodeficiência Adquirida.

\section{ABSTRACT}

Characterized as a major public health problem worldwide, infection by the Human Immunodeficiency Virus needs constant studies to identify the evolution of mortality. This study aims to exposing the sociodemographic profile of deaths from Acquired Immunodeficiency Syndrome in Brazil. It has an epidemiological, cross-sectional and retrospective design, with a quantitative approach, carried out in November 2019 based on data from the Mortality 
Information System, referring to the period from 2013 to 2017, considering the variables: region, age group, sex, race / color and schooling. The sample consisted of 62,081 cases of death from AIDS, with emphasis on the Southeast region with $42.96 \%$, in the age group of 60 to 64 years (29.33\%), male (66.25\%), with prevalence in the race / brown color variable (42\%), with 4 to 7 years of study (25.48\%). A change in the profile of these deaths in the country was revealed, with no more vulnerable population.

Keywords: Epidemiology; HIV / aids; Mortality.

\section{RESUMEN}

Caracterizada como un importante problema de salud pública a nivel mundial, la infección por el virus de la inmunodeficiencia humana necesita estudios constantes para identificar la evolución de la mortalidad. Este estudio tiene como objetivo exponer el perfil sociodemográfico de las muertes por síndrome de inmunodeficiencia adquirida en Brasil. Tiene un diseño epidemiológico, transversal y retrospectivo, con enfoque cuantitativo, realizado en noviembre de 2019 con base en datos del Sistema de Información de Mortalidad, referido al período de 2013 a 2017, considerando las variables: región, grupo de edad, sexo, raza / color y escolaridad. La muestra estuvo conformada por 62.081 casos de muerte por sida, con énfasis en la región Sudeste con 42,96\%, en el grupo de edad de 60 a 64 años (29,33\%), del sexo masculino (66,25\%), con prevalencia en la variable raza / color marrón. (42\%), con 4 a 7 años de estudio (25,48\%). Se reveló un cambio en el perfil de estas muertes en el país, sin población más vulnerable. Descriptores: Epidemiología; Mortalidad; Sindrome de inmunodeficiencia adquirida.

\section{INTRODUÇÃO}

A Síndrome da Imunodeficiência Humana Adquirida (aids) é uma doença causada pelo Vírus da Imunodeficiência Humana (HIV), que acomete o sistema imunológico do homem por destruir as células da série branca do sangue, responsáveis pela defesa do organismo contra agentes causadores de doenças. Do ponto de vista clínico, a infecção é dividida em três fases: a fase inicial, em que a sintomatologia é muito parecida com as manifestações encontradas nas síndromes gripais; seguida de uma fase assintomática, que pode se estender por décadas; e a imunossupressão clinicamente relevante (OLIVEIRA et al., 2019).

O HIV/ aids no Brasil representa relevante problema de saúde pública que atinge, de forma discrepante, diferentes segmentos da população. Desde o surgimento da doença na década de 1980, são evidentes os esforços para o enfrentamento desta, cujo números estavam entre as principais causas de morte, inferior apenas para as enfermidades cerebrovasculares, cardíacas e respiratórias, atingindo particularmente adultos jovens e pessoas em situação de pobreza. Entretanto, foi observado certo decréscimo nos últimos anos, em algumas regiões do país, enquanto em outras permanecem aumentando, apontando a necessidade de uma nova aproximação para melhor compreender esse fenômeno (BRASIL, 2019).

Alguns avanços são responsáveis por esse declínio, dentre eles, destaca-se a terapia antirretroviral de alta potência (TARV), introduzida na década de 1990, aprimorada nos primeiros dez anos do século XXI, e que obteve importantes avanços nos últimos anos, incluindo uma simplificação nos esquemas propostos, introdução de novas combinações de medicamentos com distintos mecanismos de ação e redução de efeitos adversos (WHO, 2015).

Há associação entre a TARV e a diminuição da taxa de mortalidade por aids, representando prolongamento da vida e a redução de óbito dos indivíduos acometidos por esta doença. Assim como em outros países, o Brasil vem apresentando redução da morbimortalidade, especialmente por doenças oportunistas em casos de HIV, resultando na diminuição das internações hospitalares (REIS et al., 2007).

A prevalência do HIV no Brasil é uma realidade social, e é preciso atualizar os conhecimentos 
quanto à mortalidade decorrente dessa infecção. As pesquisas epidemiológicas auxiliam na elaboração de novas políticas e intervenções à problemáticas, além de servirem de indicadores para averiguar os resultados das ações já implantadas. Portanto, este trabalho visa expor o perfil sociodemográfico dos óbitos por HIV/aids no Brasil, assim, apresentar um vislumbre dos casos notificados de mortalidade por esse problema aos profissionais e cientistas da saúde.

\section{MATERIAIS E MÉTODOS}

Trata-se de um estudo descritivo, epidemiológico, do tipo transversal, retrospectivo, de base secundária, com abordagem quantitativa, realizado em novembro de 2019, utilizando um método de documentação indireta. A primeira etapa para a sua elaboração foi a identificação do tema e da pergunta norteadora.

Os estudos epidemiológicos e quantitativos proporcionam aos pesquisadores dados mais palpáveis sobre uma determinada população, além de caracterizála melhor, fazendo com que a análise dos dados seja mais pontual e a produção de abordagens práticas ao público-alvo sejam mais específicas e individuais (SOUZA e KERBAUY, 2017). Após estas considerações, foi estruturada a seguinte questão: "quais as características sociodemográficas dos óbitos por HIV/aids no Brasil?".

A segunda etapa realizada correspondeu à coleta dos dados que integram os aspectos indicados pelos questionamentos levantados. As informações foram recolhidas através da plataforma online do Departamento de Informática do Sistema Único de Saúde (DATASUS). Essa etapa foi desenvolvida mediante pesquisa no Sistema de Informação de Mortalidade (SIM), em que estabeleceu uma amostra dos casos de óbitos pelo grupo CID-10 de doença pelo HIV, no Brasil, durante os anos de 2013 a 2017.

A terceira etapa foi selecionar as variáveis para inclusão: região, faixa etária, sexo, cor/raça e escolaridade. Os dados utilizados foram tabulados no Excel 2010, analisados descritivamente, calculando a porcentagem em frequência absoluta e relativa simples, sendo posteriormente apresentados em forma de tabelas.

$\mathrm{Na}$ quarta etapa foi realizada a análise e interpretação dos dados obtidos. Os estudos selecionados para fundamentar a discussão foram essencialmente artigos científicos, priorizando as publicações dos últimos cinco anos, nos idiomas português, inglês e espanhol. As palavras chaves adotadas foram HIV/aids; mortalidade; cor/raça; faixa etária; agravos; sexo, utilizando o operador booleano "AND", nas bases de dados indexadas na Biblioteca Virtual em Saúde (BVS) e Scielo. Esse processo ocorreu de forma gradual e contínua vislumbrando a interpretação dos dados obtidos, selecionando os estudos que tinham como temática chave os agravos decorrentes pelo HIV, com a vertente na população de risco, nas metodologias em saúde pública existentes para combater esse agravo, objetivando a relação com a prevalência de mortes por essa problemática. Todavia, ainda foi utilizado manuais do Ministério da Saúde (MS), e dados de fontes estatísticas complementares. Assim, foi possível provocar reflexividade, ajudando na construção de inter relações entre as fontes de pesquisa.

Por se tratar de um estudo por meio do DATASUS, com dados de livre acesso, base de domínio público, em que não há implicações diretas aos seres humanos, não houve a necessidade de encaminhamento ao Comitê de Ética em Pesquisa (CEP). 


\section{RESULTADOS E DISCUSSÃO}

A amostra correspondente ao número de mortes por doença pelo HIV segundo o CID-10, constituiu um total de 62.081 notificações durante os anos de 2013 a 2017. A infecção pelo HIV/aids começa a apresentar seus sintomas iniciais durante o pico de viremia, em que há uma diminuição drástica dos linfócitos T CD4+ e como resposta citotóxica, um aumento das células T CD8+. Geralmente demora cerca de 30 dias para esse surgimento, essa é a chamada fase aguda e algumas de suas características clínicas são: febre, adenopatia, faringite, mialgia, artralgia, ulcerações mucocutâneas, cefaleia, perda de peso, fadiga, náuseas e vômitos (PERDOMO-CELIS et al., 2019).

Essa etapa dura cerca de 14 dias e ocorre em $50 \%$ a $90 \%$ dos infectados (NIELSEN-SAINES et al., 2019). Durante o estágio assintomático, também conhecido por latência, o vírus se reproduz em níveis mais baixos. É comum a adoção de terapias antirretrovirais e a não apresentação de sintomas (BRASIL, 2007).
Quando o sistema imune está muito debilitado, e não consegue responder de forma eficaz ao HIV, o paciente desenvolve um quadro de síndrome que o enfraquece tornando-o suscetível a inúmeras doenças infecciosas. Nesse estágio o indivíduo é diagnosticado com a aids. Esse é o ponto da infecção que há o maior número de óbitos, contudo, com o passar dos anos, conseguiu-se retardar o surgimento da síndrome em pacientes com o vírus do HIV. Essas melhorias aconteceram em detrimento o uso de novos medicamentos e tecnologias do cuidado no campo da saúde ao portador do vírus, que no Brasil, possui acesso ao tratamento de forma gratuita pelo Sistema Único de Saúde (SUS) (BRASIL, 2005).

Na Tabela 1 estão dispostos os óbitos segundo a região do Brasil, com o maior número de notificações no Sudeste, com um total de 26.668 óbitos (42,96\%). O Nordeste aparece em seguida, com, aproximadamente, $20,89 \%$ de mortes. Ainda pode ser observado o aumento da mortalidade com o decorrer dos anos, nas regiões norte, nordeste e centro-oeste.

Tabela 1 - Número de óbitos por doença pelo HIV ocorridos por regiões do Brasil entre 2013 e 2017. Fonte: DATASUS, 2019.

\begin{tabular}{cccccccc}
\hline & \multicolumn{7}{c}{ ANO DE NOTIFICACÃO } \\
\cline { 2 - 8 } REGIÃO & $\mathbf{2 0 1 3}$ & $\mathbf{2 0 1 4}$ & $\mathbf{2 0 1 5}$ & $\mathbf{2 0 1 6}$ & $\mathbf{2 0 1 7}$ & Total & $\%$ \\
Norte & 1.135 & 1.165 & 1.177 & 1.276 & 1.240 & 5.993 & 9,65 \\
Nordeste & 2.512 & 2.469 & 2.683 & 2.693 & 2.613 & 12.970 & 20,89 \\
Sudeste & 5.540 & 5.648 & 5.437 & 5.314 & 4.729 & 26.668 & 42,96 \\
$\quad$ Sul & 2.643 & 2.547 & 2.539 & 2.439 & 2.345 & 12.513 & 20,15 \\
Centro-Oeste & 734 & 746 & 831 & 818 & 808 & 3.937 & 6,34 \\
Total & 12.564 & 12.575 & 12.667 & 12.540 & 11.735 & 62.081 & 100 \\
\hline
\end{tabular}

Esses resultados podem ser consequência da resistência, ainda presente, em abordar temas relacionados às Infecções Sexualmente Transmissíveis
(IST's), em especial, quanto ao HIV/aids, ancorando a saúde em tabus e estigmas que envolvem esses temas. Esse cenário fragilizado revela a instabilidade da rede 
de serviços de saúde em manter conectada às políticas e ações de cuidado a comunidade e grupos vulneráveis (UNAIDS, 2019).

A influência do estigma na adesão ao tratamento das pessoas que vivem com HIV/aids pode ser melhor entendida quando, pontuado por Costa e colaboradores (2018), a compreensão correta sobre a doença e o tratamento são essenciais no transcurso do processo saúde- doença- conviver com a doença (ser portador e não ser adoecido). O “não ser adoecido" faz menção ao ator social na realidade em que se encontra, que busca uma ação permanente de transformação do cotidiano para a construção de si mesmo, do outro, do seu processo de independência, sua emancipação no cuidar da saúde.

O processo de desmistificação, vai além da apresentação de dados e conteúdos científicos. Destaca-se o papel da personalidade de cada indivíduo, além da idade e escolaridade, como pontos importantes para a adesão terapêutica entre as pessoas que vivem com o HIV/aids.

Outro fator inerente ao alto índice de mortalidade pelo HIV/ aids, são as comorbidades. O vírus é responsável pelo declínio no sistema imune do seu hospedeiro humano, que quando acometido por outra enfermidade, não consegue ativar todos os mecanismos imunológicos necessários para combatêla e proteger o organismo. Outro contribuinte para essa realidade é a resistência em usar preservativo devido à falta de conhecimento ou estigma sociocultural, além de déficit na assistência especializada, especialmente na população do interior (LINS et al., 2019).

Posto isso, alguns aspectos intervencionistas seriam a exequibilidade das ações de equipe multidisciplinar, envolvendo todos os âmbitos da saúde, desde os cuidados básicos do médico e enfermeiro, como participação do psicólogo e nutricionista. Todavia é preciso que exista interdisciplinaridade no trabalho desses profissionais, sendo uma possível saída para dar-se conta do objeto de trabalho da saúde, pela possibilidade de cuidar dos pacientes portadores desta infecção, de forma individual ou coletiva e em todas as fases do processo de viver saúde- doença (COSTA et al., 2018).

Diante disso, questiona-se o baixo investimento nessas regiões, ou o emprego ineficaz de recursos destinados ao fortalecimento das políticas de saúde. Em detrimento a existência desse cenário, o Brasil aderiu ao Plano de Ação para a prevenção e o controle do HIV e de IST's 2016-2021, desenvolvido pela OMS em 2016, que reflete sobre as prioridades de prevenção e disponibilidade de recursos para as populações e regiões mais afetadas pelo HIV. Dessa forma possibilita o impedimento de possíveis complicações da doença oferecendo assistência igualitária para todos.

A Tabela 2 apresenta os dados sociodemográficos elencados para esse estudo, com destaque para as faixas etárias de 60 a 64 anos com $18.210(29,33 \%)$ dos casos, seguidos por 40 a 59 anos com $17.260(27,80 \%)$.

Os dados dispostos na primeira parte da Tabela 2 revela relação direta com as atividades em saúde desenvolvidas com o público idoso, destacando o fato de os serviços de saúde não implementarem ações direcionadas ao cuidado sexual da população idosa, permitindo a permanência de lacunas e preenchimento de estigmas (GIRONDI et al., 2012). Araújo e Carlos (2018) mencionam que, devido aos aspectos culturais e históricos, há um mito no cotidiano do indivíduo idoso e no campo da sexualidade em que, o processo do envelhecimento está ligado a um desprendimento da vida sexual. Esse fator limita os profissionais de saúde na abordagem da sexualidade com o público senil, olvidando a investigação dos riscos que esses indivíduos estão expostos. 
Outro aspecto associado aos índices elevados de contaminação na população idosa refere-se à negligência no uso do preservativo, pois acredita-se que a camisinha deve ser utilizada como método contraceptivo que deve ser indubitavelmente usada na fase reprodutiva, contrariando o verdadeiro intuito do método de barreira na minimização das IST's em todas as relações sexuais. Ademais a escassez de informações relacionadas aos métodos de prevenção, diagnóstico precoce, sinais e sintomas, testes rápidos que fortalecem as políticas de prevenção e diagnóstico precoce.

Tabela 2 - Distribuição dos casos de óbitos por doença pelo HIV por faixa etária, sexo e raça. Brasil, 20132017. Fonte: DATASUS, 2019.

\begin{tabular}{|c|c|c|}
\hline Faixa Etária & $\mathrm{n}=$ & $\%$ \\
\hline$<1$ ano & 138 & 0,22 \\
\hline $1-4$ & 82 & 0,13 \\
\hline $5-9$ & 64 & 0,10 \\
\hline $10-14$ & 82 & 0,13 \\
\hline $15-19$ & 598 & 0,96 \\
\hline $20-39$ & 7634 & 12,29 \\
\hline $40-59$ & 17.260 & 27,80 \\
\hline $60-64$ & 18.210 & 29,33 \\
\hline $65-79$ & 11.480 & 18,50 \\
\hline $65-69$ & 4.636 & 7,47 \\
\hline $70-79$ & 1.391 & 2,24 \\
\hline$\geq 80$ & 358 & 0,57 \\
\hline Ignorada & 148 & 0,24 \\
\hline \multicolumn{3}{|l|}{ Sexo } \\
\hline Masculino & 41.134 & 66,25 \\
\hline Feminino & 20.929 & 33,71 \\
\hline Ignorado & 18 & 0,028 \\
\hline \multicolumn{3}{|l|}{ Cor/Raça } \\
\hline Branca & 24.617 & 39,65 \\
\hline Preta & 8.461 & 13,62 \\
\hline Amarela & 135 & 0,22 \\
\hline Parda & 26.071 & 42 \\
\hline Indígena & 137 & 0,22 \\
\hline Ignorado & 2.660 & 4,28 \\
\hline Total & 62.081 & 100 \\
\hline
\end{tabular}

É imprescindível o estabelecimento de estratégias para diagnóstico precoce e implementação de tratamento imediato, interrompendo a cadeia de transmissão, o que pode ser viabilizado pela inserção de ampla anamnese, pelos profissionais de saúde, inclusive com levantamento sobre a história sexual, com oferta de sorologia, nos casos de história de IST e em outras situações de vulnerabilidade. Para tanto, fazse necessária a educação permanente dos profissionais, na temática, de forma que possam contribuir para a implantação exitosa das políticas de promoção e prevenção às IST/aids mediado pelo uso de tecnologias educativas no desenvolvimento de estratégias na promoção do cuidado e educação sexual (MOREIRA, 2017).

A segunda parte da Tabela 2 revela que mais da metade dos óbitos, com 41.134 (66,25\%) refere-se aos dados do sexo masculino. Segundo a UNAIDS (2017), indivíduos do sexo masculino são os que menos procuram fazer o teste para o HIV, que é um instrumento que auxilia no diagnóstico da infecção. Com isso é possível identificá-la precocemente, prevenindo as chances de desenvolver a aids. Contudo, essa realidade ainda é distante, pois quando o indivíduo é diagnosticado tardiamente, é possível observar sinais e sintomas do desenvolvimento da síndrome, evoluindo com piores complicações, podendo evoluir com celeridade para óbito.

Esses números podem ser comparados com os dados obtidos na pesquisa de Almeida e colaboradores (2020), que apresentaram os casos diagnosticados de HIV no Brasil, durante 2013 a 2017. Foi identificado um percentual próximo entre ambos, sendo o número de diagnósticos de 89.757 e o número de mortos 62.081. Ou seja, a quantidade de óbitos corresponde a mais da metade dos casos notificados. Dessa forma, é possível afirmar com mais precisão a dificuldade na busca do tratamento após o diagnóstico (BRASIL, 2018).

Outro fator relacionado ao homem e as dificuldades na adesão do tratamento e diagnóstico precoce possui uma relação culturalmente ancorada, 
uma vez que, o homem representa figura de virilidade e força extrema, o qual enxerga a doença como fonte de fraqueza. Portanto, a procura por assistência de saúde é vislumbrada como algo que impede a sua imagem masculina ideal, e o tratamento o impõe condição de fragilidade, em que o homem é colocado sob uma posição de cuidado, podendo ser interpretada por submissão à um tratamento e ou profissional (CORTEZ et al., 2017).

Essa problemática não é exclusiva da infecção pelo HIV/aids, já que no país a população masculina é bastante resistente e negligente no que compete aos cuidados de saúde, representando grande desafio aos profissionais da saúde na elaboração de estratégias que modifiquem esse quadro, especialmente no que tange a prevenção e o diagnóstico precoce, facilitando a adesão ao tratamento e práticas do cuidado. Nesse quesito o empoderamento masculino acerca do autocuidado pode auxiliar nessa abordagem, já que através desse método, defendido pela enfermeira Dorothea Orem (2006), o paciente assume uma posição ativa no seu processo de saúde e doença.

A terceira parte da Tabela 2 apresenta dados sociodemográficos quanto a cor/raça. Observa-se percentual elevado no número de óbitos em indivíduos de cor parda, com um total de 26.071 (42\%). A literatura relaciona esse resultado com o nível social e econômico, já que a maioria das pessoas autodeclaradas pardas, no Brasil, vivem em zonas de difícil implementação de promoção da saúde. Adicionando a este quesito as condições precárias de vida como moradia, ausência de saneamento básico, alimentação, escolaridade e acesso a saúde, dificultando assim a adesão ao tratamento resultando em complicações da doença (MELO et al., 2019).

Outro dado que chama atenção é o número de óbitos da população branca quando confrontados com o percentual de indivíduos negros. Há discrepante diferença nos valores. A primeira apresenta dados extremamente superiores, contrapondo, a segunda classe populacional em que a quantidade é bem menor. Ao resgatar aspectos históricos, o Boletim Epidemiológico de aids e HIV (BRASIL, 2012), do MS, mostrou que entre 2000 e 2011 os óbitos por essa síndrome ocorridos na população negra, cresceu $17 \%$ (contudo, foi considerado a população parda nesse percentual), entretanto, entre brancos autodeclarados, registrou a atenuação de $9 \%$ nos valores no mesmo tempo.

Algumas mudanças são enaltecidas no atual contexto no que compete às questões de saúde, podendo ser indicativo de boa adesão terapêutica à população autodeclarada preta. Contudo, ainda se faz necessário a quebra do estigma existente socialmente, em que a população branca não "caracteriza população de risco", fortalecendo cuidados equivocados e negligentes que comumente são acompanhados por práticas inadequadas em saúde.

A escolaridade dos indivíduos que vieram a óbito após a infecção pelo HIV no Brasil é representada na Tabela 3. Aqueles que apresentam de quatro a sete anos de estudo contém o destaque em quantidade de mortes, com cerca de 15.819 (25,48\%) das notificações.

Tabela 3 - Distribuição dos casos de óbitos por doença pelo HIV segundo a escolaridade. Brasil, 20132017. Fonte: DATASUS, 2019.

\begin{tabular}{ccc}
\hline Escolaridade & $\mathbf{n}=$ & $\%$ \\
\hline Nenhuma & 3.483 & 5,61 \\
1 a 3 anos & 12.475 & 20,09 \\
4 a 7 anos & 15.819 & 25,48 \\
8 a 11 anos & 13.294 & 21,41 \\
12 anos e mais & 3.760 & 6,06 \\
Ignorado & 13.250 & 21,34 \\
\hline Total & 62.081 & 100 \\
\hline
\end{tabular}

Este resultado é relacionado a insuficiência de informações e entendimento sobre o que é a doença, prevenção, formas de tratamento e transmissão (MELO et al., 2019). Em contrapartida, os indivíduos 
com 12 anos ou mais de escolaridade apresentam baixa taxa de mortalidade, podendo ser atribuído ao elevado acesso ao conhecimento e por conseguinte, maior emancipação quanto ao autocuidado e práticas preventivas de agravos à saúde.

A disseminação de informações sobre a aids é bastante limitada. A TARV é motivo de dúvidas entre pacientes e indivíduos saudáveis, uma vez que, não objetiva a cura do paciente, contudo diminui significativamente e comprovadamente a morbimortalidade pela Aids. Após iniciado o tratamento farmacológico, o paciente aumenta a sua expectativa de vida em números expressivos, variando quanto ao tempo que levou para iniciar o tratamento e o estilo de vida adotado (ROSSI et al., 2012).

O paciente pode apresentar descrença quanto à efetividade do tratamento, já que não é visado a cura da infecção. Outra questão importante é a relação dessa terapia e transmissão do vírus. A Organização das Nações Unidas (ONU), a partir do programa UNAIDS (2017), enfatiza a abordagem do declínio expressivo da carga viral, o indivíduo possui riscos reduzidos em transmitir o vírus. Essa informação é utilizada como arma de dois fios, uma vez que pode encorajar a realização de práticas sexuais sem o devido uso de preservativo, especialmente se existir déficit informativo pela população acerca da doença e tratamento. Por isso, questões que elucidem melhor essas e outras informações para a sociedade são altamente necessárias para modificar essa realidade social e problemática de saúde pública.

\section{CONCLUSÃO}

Os casos de infecção por HIV/aids persistem no Brasil, mesmo apresentando uma diminuição gradual dos dados no decorrer dos anos, pela análise de 2013 a 2017, sendo restrito às regiões sul e sudeste. Entendendo que essa é uma doença crônica que não possui cura, mas possui formas de transmissão conhecidas, com prevenção gratuita e acessível, além de tratamento gratuito, esses dados são preocupantes.

Torna-se relevante o planejamento de ações mais eficazes mediada pela implementação de novas metodologias informativas, educacionais e participativas que desmistificam a infecção, assim como exalte o uso do preservativo, como melhor forma de prevenir a disseminação do vírus e interrupção do ciclo de contaminação. Podendo ser explorado os recursos digitais, como uso de vídeos, materiais em redes sociais, infográficos e abordagem específica e direcionada à um público, especialmente na população mais idosa, do sexo masculino.

A popularização do conhecimento é apresentada como método para o rompimento de estigmas. Bem como atenção às práticas que exaltem o autocuidado em infectados e saudáveis, visando a promoção e prevenção de comorbidades e óbitos, especialmente nas populações mais vulneráveis, necessitando a elaboração de métodos mais personalizados, individuais e integrais, que holisticamente implementem cuidados a médio e longo prazo. Dessa forma, contemplaria o público com baixa escolaridade e tornaria $\mathrm{o}$ acesso à informação mais democrático e igualitário.

Este estudo utilizou um banco de dados público e caracterizado como secundário, coletados e disponibilizados previamente por uma fonte governamental, estando sujeito à realidade das subnotificações, caracterizando como limitação do estudo, já que limita o conhecimento real do atual panorama da doença no Brasil. Entretanto, por se tratar de dados oficiais, de nível nacional e de carácter obrigatório em todos os serviços de saúde, os resultados obtidos permitiram interpretação suficiente para sanar os objetivos propostos.

Todos os autores declararam não haver qualquer potencial conflito de interesses referente a este artigo. 


\section{REFERÊNCIAS}

ALMEIDA, H.M.D.S; RAMOS, A.C.A.; NASCIMENTO, A. G.; CHAVES, B.F.B.; BATISTA, J.L.F.P.; OLIVEIRA,R.R.. Análise Epidemiológica De Casos Notificados Por Hiv/Aids No Brasil. In: S. B. FERREIRA; P. B. FERREIRA. (org.). Saúde do Ensino à Pesquisa. 1ed.: Editora Pasteur, v. 1, p. 37 47; 2020.

ARAÚJO, L.F; CARLOS, K.P.T. Sexualidad en velhice: un estudio sobre el envejecimiento LGBT. Psicología, Conocimiento y Sociedad., v. 48, n. 1, p. 188-205, 2018.

BRASIL. 2019. Boletim Epidemiológico AIDS e HIV 2019. Disponível em < http://www.aids.gov.br/pt-br/centrais-deconteudos/boletins-epidemiologicos-vertical >. Acesso em: 15/08/2020

BRASIL. 2012. Boletim Epidemiológico AIDS e HIV: versão preliminar. Disponível em: < http://bvsms.saude.gov.br/bvs/periodicos/boletim_epi dem_hivaids_2012.pdf > Acesso em: 10/11/2019

BRASIL. 2018. Boletim Epidemiológico HIV/Aids. Disponível em: < http://www.aids.gov.br/ptbr/pub/2019/boletim-epidemiologico-de-hivaids-2019 > Acesso em: 10/11/2019

BRASIL. 2005. Guia de vigilância epidemiológica. In: Ministério da Saúde. Disponível em: $<$ http://bvsms.saude.gov.br/bvs/publicacoes/guia_vigi lancia_epidemiologica_7ed.pdf $>$ Acesso em: 17/07/2019.

BRASIL. 2019. Departamento de Informática do SUS (Datasus). Sistema de Informação sobre Mortalidade. Disponível em: < http://www.datasus.gov.br >. Acesso em: 15/11/2019

BRASIL. Recomendações para terapia antiretroviral em adultos e adolescentes infectados pelo HIV. Ministério da Saúde. 6th ed.; 2007.

CORTEZ, M.B; TRINDADE, Z.A; MENANDRO, M.C.S. Racionalidade e sofrimento: homens e práticas de autocuidado em saúde. Psicologia, Saúde \& Doenças. v. 18, n. 2, p. 556-566, 2017.

COSTA, L.M.C.B.V; CASSEB, J.S.R; GASCON, M.R.P; FONSECA, L.A.M. Características de personalidade e adesão ao tratamento em pacientes jovens portadores de HIV. Revista da SBPH. v. 21, n. 1, p. 06-35, 2018.

GIRONDI, J. B. R; ZANATTA, A. B.; BASTIANI, J. A. N.; NOTHAFT, S. S; SANTOS, S. M A. Perfil epidemiológico de idosos brasileiros que morreram por síndrome da imunodeficiência adquirida entre 1996 e 2007. Acta Paulista de Enfermagem. v. 25, n. 2, p. 302-307, 2012.

LINS, M.E.V.S; JESUS, J.B; OLIVEIRA, J.F; RÊGO, G.G; MATOS, A.V.M; WANDERLEY, N.B; ASANO, N.M.J; SOUZA, M.B.R. Perfil epidemiológico de óbitos por HIV/AIDS na região nordeste do Brasil utilizando dados do sistema de informação de saúde do DATASUS. Brazilian Journal of Health RevieW, v. 2, n. 4, p. 2965-2973, 2019.

MELO, M.C; MESQUITA, F.C; BARROS, M.B.A; LA-ROTTA, E.I.G; DONALISIO, M.R. Sobrevida de pacientes com aids e associação com escolaridade e raça/cor da pele no Sul e Sudeste do Brasil: estudo de coorte, 1998-1999. Epidemiologia e Serviços de Saúde. v. 28, n. 1, e2018047, 2019.

MOREIRA, A.S. Elaboração de uma tecnologia educativa para promoção da sexualidade. Cuiabá, MG. MONOGRAFIA. Universidade Federal de Mato Grosso; 2017.

NIELSEN-SAINES, K; MITCHELL, K; KERIN, T; FOURNIER, J; KOZINA, L; ANDREWS, B; CORTADO, R; BOLAN, R; FLYNN, R; ROTHERAM, M.J; ABDALIAN, S.E; BRYSON, Y. Acute HIV Infection in Youth: Protocol for the Adolescent Trials Network 147 (ATN147) Comprehensive Adolescent Research and Engagement Studies (CARES) Study. JMIR Research Protocol. v. 8, n. 1, p. 01-14, 2019.

OLIVEIRA, V.S; RODRIGUES, B.M; AQUINO, E.C. Mortalidade por AIDS no Centro-Oeste brasileiro em 10 anos: uma análise de séries temporais por faixas etárias. Revista Saúde Coletiva UEFS, v.9, p.212217, 2019.

OREM, D.E. Part One: Dorothea E. Orem's self-care deficit nursing theory. In M.E. PARKER, Nursing theories and nursing practice. Philadelphia. 2nd ed., p. 141-149. 2006.

PERDOMO-CELIS, F; TABORDA, N.A; RUGELES, M.T. CD8+ T-Cell Response to HIV Infection in the Era of Antiretroviral Therapy. Frontiers in Immunology v. 10, n. 1896, p. 01-19, 2019.

REIS, A.C; SANTOS, E.M; CRUZ, M.M. A mortalidade por aids no Brasil: um estudo exploratório de sua evolução temporal. Epidemiologia Serviços Saúde. Brasília, v. 16, n. 3, p. 195-205, 2007.

ROSSI, S.M.G; MALUF, E.C.P; CARVALHO, D.S; RIBEIRO, C.E; BATTAGLIN, C.R.P. Impacto da terapia antirretroviral conforme diferentes consensos 
de tratamento da Aids no Brasil. Revista Panamericana Salud Publica v. 32, n. 2, 2012.

SOUZA, K.R; KERBAUY, M.T.M. Abordagem quanti-qualitativa: superação da dicotomia quantitativa-qualitativa na pesquisa em educação. Educação e Filosofia v. 31, n. 61, p. 21-44, 2017.

UNAIDS. 2019. Estudo revela como o estigma e a discriminação impactam pessoas vivendo com HIV e AIDS no Brasil. Disponível em: < https://unaids.org.br/2019/12/estudo-revela-como-oestigma-e-a-discriminacao-impactam-pessoasvivendo-com-hiv-e-aids-no-brasil/> Acesso em: 20/03/2021.

UNAIDS. 2017. Homens são menos propensos a buscar tratamento para HIV e têm mais chances de morrer por causas relacionadas à AIDS, diz
UNAIDS.

Disponível

em:

$<$ https://unaids.org.br/2017/11/homens-sao-menospropensos-buscar-tratamento-para-hiv-e-tem-maischances-de-morrer-por-causas-relacionadas-aids-dizunaids/\#more-7830\%20UNAIDS\%20-

\%20Brasil\%20-\%20Dia\%2030-nov-2017> Acesso em: 10/11/2019.

UNAIDS. 2017. O que significa estar com a carga viral indetectável?. Disponível em: https://unaids.org.br/2017/07/indetectavel-saudepublica-e-supressao-viral-do-hiv/ > Acesso em: 20/03/2021.

WHO. Guideline on when to start antiretroviral therapy and on pre-exposure prophylaxis for HIV. Geneva: WHO; 2015. Disponível em < http://www.who.int/hiv/pub/guidelines/earlyreleasearv/en/ >. Acesso em: 17/07/2019 